\title{
The Impact of Work Centrality and Type of Work on Life Satisfaction: an Exploration of Global Respondents
}

\author{
Vallari Chandna ${ }^{1}$
}

\begin{abstract}
Organizations have over time, become concerned with non-work aspects of their employees' lives such as their life satisfaction and their happiness. This is because extant research has shown these states of being, truly have an impact on their job performance, intra-organizational relationships, and other important workrelated outcomes. The World Values Survey assesses the cultural values of people across the world, what is important to them in life, their physical and mental state of being, and other valuable information. Using a random portion of this international dataset and drawing on the literatures pertaining to work centrality and meaning of work, the hypothesized model is developed to test the relationship between work centrality and the flow at work (i.e., type of work done) on the life satisfaction of individuals. These aspects of the work domain were found to have a minimal direct impact on life satisfaction leading to the reaffirmation that the different domains (work, family, values) have unequal impacts on life satisfaction and within each domain, different components have differing levels of impact as well.
\end{abstract}

Keywords: life satisfaction, work life balance, work centrality, work ethic JEL classifications: I31, MO,

DOI: $10.24818 / \mathrm{REJ} / 2021 / 81 / 04$

\section{Introduction}

Life satisfaction cannot exist in isolation from the work lives of individuals. Many organizational outcomes and desired work behaviors are often antecedents or consequences of life satisfaction. Job satisfaction and life satisfaction are deeply linked (Unanue et. al., 2017). In addition to the work domain, the non-work domain consisting of family, friends, and values, exerts considerable influence on life satisfaction (Greenhaus et al., 2003). Different scholars have examined life satisfaction as it relates to personality traits, work outcomes, and work-related antecedents (Diener et al., 2003). However, this paper develops a universal model using data from participants from all over the world, examining work centrality which is the fundamental work-related value dimension and how engaging certain work is considered, to determine their relationship to life satisfaction of individuals. \begin{tabular}{l}
${ }^{1}$ PhD. Associate Professor of Management, Austin E. Cofrin School of Business, University of \\
Wisconsin-Green Bay, ORC ID: 0000-0002-5169-8010, e-mail: chandnav@uwgb.edu \\
\hline Year XXIV no. 81
\end{tabular} 
Research in this area has been restricted to within-country research or limited comparative research (Blakely et al., 2005; English and Misumi; 1986). However, in the proposed model, data from individuals from multiple countries are used to assess whether there is a common element binding our work lives and life satisfaction together. The research question answered in this study is: What is the effect of work centrality and type of work done on the life satisfaction of individuals across the world?

\section{Literature Review}

Life satisfaction and other aspects of subjective wellbeing are relevant areas of study for management scholars (Blanchflower and Oswald, 2011). Work plays an integral role in our lives and it affects our life satisfaction levels (Karabati et al., 2021). The question remains how certain aspects of our work lives i.e., our attitudes towards work and the kind of work we do, affect our life satisfaction. The kind of work we do, relates to flow theory which is about the higher meaning derived from immersion in engaging tasks.

Life satisfaction: Life satisfaction relates to multiple organizational outcomes such as career satisfaction, job performance, organizational commitment, job satisfaction, turnover intentions, and organizational citizenship behavior (Burke, et al.; 1999, Barsky et al., 2004; Greguras and Diefendorff, 2010; De Clercq, et. al., 2021). Life satisfaction itself is affected by different aspects of an individual's life comprising both the work and non-work domain. Life satisfaction is generally equated with subjective happiness or personal contentment (Linley et al., 2009) The two perspectives used are the "bottom-up" perspective wherein life satisfaction is a function of being satisfied with different life domains and the "top-down" perspective which states that life satisfaction is a function of stable traits (Brief et. al, 1993; Diener, 1984). In this study, both approaches are employed i.e., the topdown approach is applied in studying life satisfaction as it relates to the trait of work centrality. At the same time, its relationship with type of work is examined thereby utilizing the bottom-up approach. Within the bottom-up perspective, there exist two categories: the first includes the needs- satisfaction theories and the second includes activity-based theories (Diener et al., 2002). The former essentially states that when employees' needs are satisfied, their life satisfaction increases. However, it is the latter, the activity-based theoretical approach that is of relevance to this study. The main theory within this is the theory of flow (Csikszentmihalyi, 1990), which argues that certain activities increase the likelihood of an individual experiencing a state of being in which they are so engrossed in an activity that 
nothings else matters to them because the "enjoyment" associated with the activity is high and keeps the individual involved.

Work centrality: The role played by work in the socio-economic structure has varied over time and historically, it has been dissimilar in different cultures. It is widely acknowledged that the Protestant work ethic influenced how we perceive work and the importance of work in our lives (Saal, 1978). Where religious influences did not influence work attitudes or have since ceased to influence them, work as a virtue is still engrained via education, sports, advertisements, etc. (Beder, 2000; James, 2017). The actual term was popularized by England and Misumi (1986). Their conceptualization of work centrality focused not on how work is central or important to an individual; instead, it encompasses the differing individual rationales for work importance. Carr and colleagues (2007) observed that individuals high on work centrality generate strong work-related values. Individuals with high work centrality have lifegoals that revolve around work and this workcentric attitude governs their priorities, and how they allocate their "resources" such as time and energy (Bagger and Li, 2012). Work centrality does not vary depending on the conditions in a specific work setting and thus is relatively stable attitude of an individual towards work (Mannheim, 1993; Bal and Kooij, 2011).

Type of Work: The importance of work in individuals' lives is rarely in question, having long been established by many scholars as occupying a central and fundamental role in peoples' lives (Mannheim, 1975; England and Misumi, 1986; Ruiz Quintanilla, 1990). But some aspects of work are indeed more relevant than others. While work centrality is an attitude towards work (i.e., a relatively stable trait), whether work is meaningful and engaging is an additional aspect that deserves scholarly attention. According to Dejours and Deranty (2010), work demands a kind of "practical intelligence that is inherently inventive and creative" (pg. 170) though the degree of this demand varies across jobs. Work that is more challenging or creative, keeps individual more engaged and is in line with Csikszentmihalyi's flow theory which posits that such work keeps individuals engaged and engrossed (Myers and Diener, 1995). Thus, being involved in challenging activities which are meaningful and rewarding to the individual while also having definite, clear goals, keeps individuals engrossed and immersed in the activity and will likely lead to greater life satisfaction. The type of work i.e., flow at work is a function of how cognitive and creative the work is, as compared to routine and unchallenging. The meaningfulness of their work contributes to individuals' positive self-conceptions, self-worth, personal fulfillment, work motivation, job satisfaction and individual performance (Kahn, 1990).

Year XXIV no. 81

September 2021 


\section{Research Methodology}

The proposed model, using these operationalized constructs, is as follows:

Figure 1. Hypothesized Model of Relationships

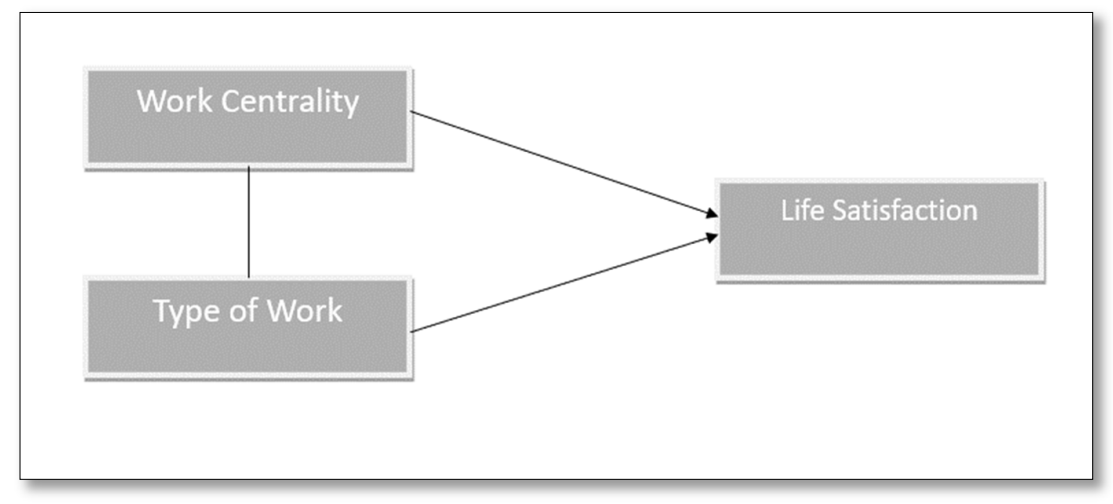

Analysis: The World Values Survey dataset was used containing data from individuals across the world from different societies, varied socioeconomic groups, age brackets, and a multitude of diverse backgrounds. This is a collaborative global project with publicly accessible data. While the original dataset contains thousands of surveys, a random sample of 350 was chosen of equally distributed male-female participants, with ages varying from 18-82 years. The frequency of age distribution was normal. The work centrality construct was measured using three items and the engaging work construct was measured using two items. The reliability coefficient, Cronbach's Alpha, for these two "miniature scales" were found to be around the .60 level using SPSS which is acceptable for exploratory work especially as scale brevity restricts the achievement of high coefficients (Bearden et al., 2011). The life satisfaction scale was a single item. The convergent and discriminant validity of the various constructs was examined. The extraction method used was principal component analysis and the rotation method used was Varimax rotation. Other survey items, some pertaining to similar constructs, were added for comparison purposes. The three work centrality items converged together with factor loadings of $.735, .728$ and .647 as did the two items pertaining to engrossing work which had factor loadings of .749 and .734 . No cross-loadings were seen above the .40 level. Using AMOS as a software tool the model was designed to test whether the work centrality attitudes of individuals and the engrossing nature of their work (flow at work), predicted the life satisfaction of individuals from different parts of the world. 


\section{Results}

For the sample consisting of $\mathrm{N}=350$ respondents, a Chi-square of 12.01 was obtained with seven degrees of freedom at a probability level=.100. The chi-square table value is 12.2 making this acceptable (Barrett, 2007). Various fit indices were examined to determine the model fit. Regarding absolute fit indices, the model had a GFI $=.989$ and an AGFI $=.967$ which is above the acceptable thresholds as per the literature pertaining to the same, with higher numbers indicating better fit (Tabachnick and Fidell, 2007). The third absolute fit index examined was the RMSEA which was found to be .045. Good model fit is indicated by an RMSEA of less than .07 with excellent fit being achieved if RMSEA is less than .03 (Steiger, 2007). This model appears to be good with reference to this range of values. From among the incremental fit indices, the CFI is examined and was found to be .976 . The acceptable threshold for which is 0.95 as well with higher numbers being indicative of better model fit ( $\mathrm{Hu}$ and Bentler, 1999). The squared multiple correlations for the model was 0.05 which indicates that the two constructs examined i.e. work centrality and flow at work (engaging work) account for only $5 \%$ of an individuals' life satisfaction.

Figure 2. Relationships based on analysis of data 


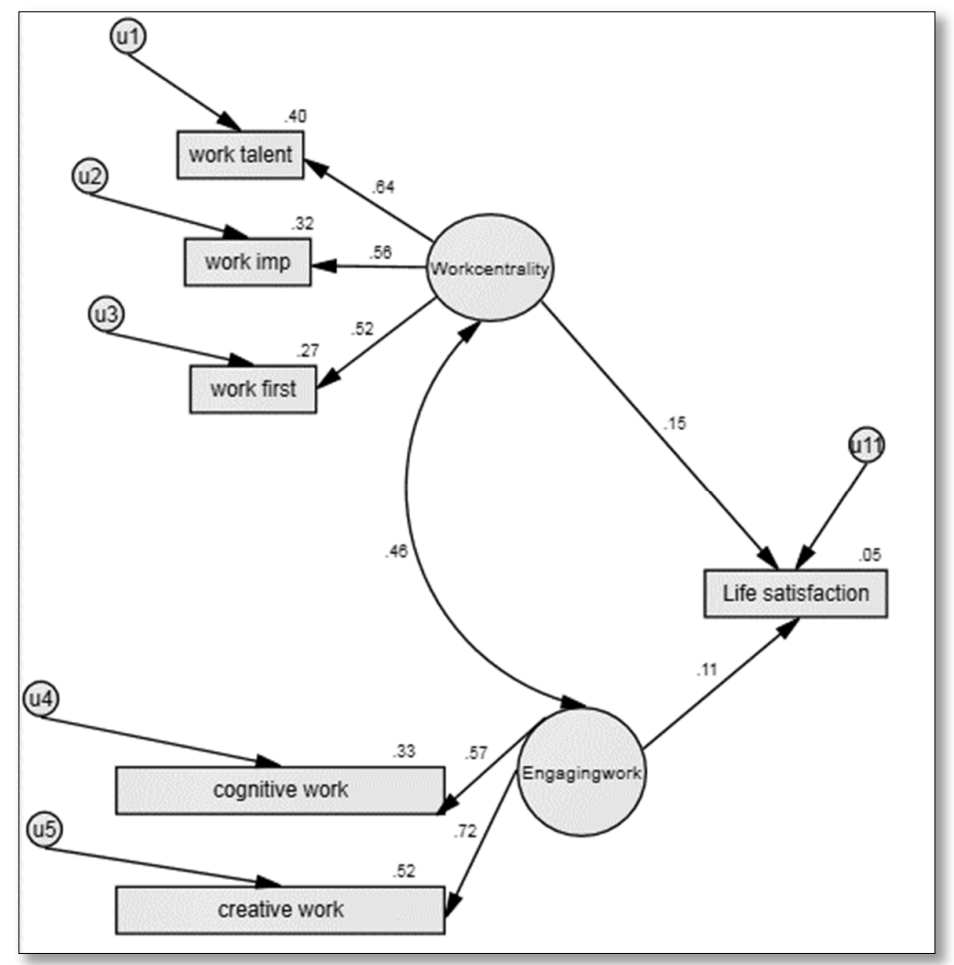

\section{Discussion}

While integral to individual's lives, not all aspects of the work life such as work centrality and flow at work play as important a role in individuals' life satisfaction as this study indicates. When examined specifically the relationship between the overall work domain and life satisfaction has been found to be quite weak (Rode, 2004). Usually, the relationship between job satisfaction and work satisfaction is studied to understand the relationship between work domain-related aspects and life satisfaction; Near and Rechner (1993) found that it explains less than $1 \%$ of the variance in life satisfaction. Thus, despite its pivot role, not all components of work are as relevant or as impactful on individuals' life satisfaction. The minimal impact of work centrality and flow at work on life satisfaction found in the current study seems to be reflective of the fact that not all life domains have the same importance when it comes to life satisfaction and even within each domain, the sub-domains have varied impacts. Instead, these facets of the work-domain only account for about $5 \%$ of the life satisfaction of individuals. 


\section{Conclusion}

This study thus adds to the multiple attempts at finding relevant aspects of the work domain that are related or unrelated to life satisfaction to better understand what it is that drives individuals' life satisfaction. Both work centrality and flow at work were chosen as the literature indicated them to be relevant work domain facets from a scholarly perspective and they hold practical significance for managers. It appears that neither has as strong an impact on life satisfaction as extant literature may lead us to conclude, but this is not surprising as the life satisfaction literature does show that only certain aspects of work seem to have a bearing on people's life satisfaction directly. While it is commendable that organizations are concerned with their employees' life satisfaction, hiring people that are more work-centric in the hopes that such people are more satisfied with life in general is a faulty assumption. However, it is still important for organizations to focus on employees' needs like flow at work; the reason for the focus should be the attainable end goal of job satisfaction and not the loftier goal of life satisfaction.

Work centrality of individuals and their type of work varies within countries and across the world- the cross-national data provided by the World Values Survey, provided a comprehensive dataset to study whether the impact of these aspects on life satisfaction are universal in nature. Interpretations of the meaning of life literature and the research on work centrality might lead to inferring that these are important to life satisfaction. However, there are multiple domains of family, friends, and community, that also contribute to life satisfaction. Perhaps as scholars of business there is a tendency to over-emphasize the importance of the work domain in life satisfaction. Work attitudes and the flow at work do not seem to impact individual life satisfaction significantly by themselves. To understand which aspects of the work domain are in fact related to life satisfaction requires us to look elsewhere: at other aspects of work and at other domains.

\section{References}

Bal, P.M. and Kooij, D. (2011) "The relations between work centrality, psychological contracts, and job attitudes: The influence of age", European Journal of work and organizational psychology, Vol. 20 No. 4, pp. 497-523.

Barrett, P. (2007) “Structural Equation Modelling: Adjudging Model Fit", Personality and Individual Differences, Vol. 42 No. 5, pp. 815-24.

Barsky, A., Thoresen, C. J., Warren, C. R. and Kaplan, S. A. (2004) "Modeling negative affectivity and job stress: A contingency-based approach", Journal of Organizational Behavior, Vol. 25, pp. 915-936. 
Bearden, W.O., Netemeyer, R.G. and Haws, K. (2011) Handbook of Marketing Scales: Multi-Item Measures for Marketing and Consumer Behavior Research, 3rd Edition, Palo Alto, CA: Sage Publications, Inc.

Beder, S. (2000) Selling the Work Ethic, Scribe, Melbourne.

Blakely, G. L., Srivastava, A. and Moorman, R.H. (2005) “The Effects of Nationality, Work Role Centrality, and Work Locus of Control on Role Definitions of OCB", Journal of Leadership \& Organizational Studies, Vol. 12 No. 1, ProQuest, pp. 103.

Blanchflower, D. G. and Oswald, A. J. (2011) "International happiness: A new view on the measure of performance", Academy of Management Perspectives, Vol. 25, pp. 6-22.

Brief, A. P., Butcher, A. H., George, J. M. and Link, K. E. (1993) "Integrating bottom-up and top-down theories of subjective well-being: The case of health", Journal of Personality and Social Psychology, Vol. 64, pp. 646-653.

Britt, T. W., Adler, A. B. and Bartone, P. T. (2001) "Deriving benefits from stressful events: The role of engagement in meaningful work and hardiness", Journal of Occupational Health Psychology, Vol. 6, pp. 53-63.

Burke, R. J., Divinagracia, L. A. and Mamo, E. (1999) "Predictors of life satisfaction among Filipino managerial and professional women", Psychological Reports, Vol. 84, pp. 805-808.

Csikszentmihalyi, M. (1990) "Flow: The Psychology of Optimal Experience", New York: HarperCollins.

England, G. W. and Misumi, J. (1986) "Work centrality in Japan and the United States", Journal of Cross-Cultural Psychology, Vol. 17, pp. 399-416.

De Clercq, D., Brieger, S. A. and Welzel, C. (2021) "Leveraging the macro-level environment to balance work and life: an analysis of female entrepreneurs' job satisfaction", Small Business Economics, Vol. 56 No. 4, pp. 1361-1384.

Dejours, C. and Deranty, J. (2010) "The Centrality of Work", Critical Horizons, Vol. 11 No. 2, pp. 167-180

Diener, E. (1984) "Subjective well-being”, Psychological Bulletin, Vol. 95, pp. 542-575.

Diener, E., Emmons, R. A., Larsen, R. J. and Griffin, S. (1985) "The satisfaction with life scale",

Journal of Personality Assessment, Vol. 49 No. 1, pp. 71-75.

Diener, E., Oishi, S. and Lucas, R. (2002) "Subjective well-being: The science of happiness and life satisfaction", In C. R. Snyder and S. J. Lopez (Eds.), The handbook of positive psychology, pp. 63-73, New York: Oxford University Press.

Diener, E., Oishi, S. and Lucas, R. E. (2003) "Personality, culture, and subjective well-being: Emotional and cognitive evaluations of life", Annual Review of Psychology, Vol. 54, pp. 403-425. 
Greenhaus, J. H., Collins, K. M. and Shaw, J. D. (2003) "The relation between work-family balance and quality of life", Journal of Vocational Behavior, Vol. 63, pp. 510-531.

Greguras, G. J. and Diefendorff, J. M. (2010) "Why does proactive personality predict employee life satisfaction and work behaviors? A field investigation of the mediating role of the self-concordance model", Personnel Psychology, Vol. 63, pp. 539-560.

Hu, L.T. and Bentler, P.M. (1999), "Cutoff Criteria for Fit Indexes in Covariance Structure Analysis: Conventional Criteria Versus New Alternatives", Structural Equation Modeling, Vol. 6 No. 1, pp. 1-55.

James, S. (2017) "Making a Living, Making a Life: Work, Meaning and SelfIdentity", Routledge.

Kahn, W. A. (1990). "Psychological conditions of personal engagement and disengagement at work", Academy of Management Journal, Vol. 33 No.4, pp. 692-724.

Karabati, S., Ensari, N. and Fiorentino, D. (2019) "Job satisfaction, rumination, and subjective well-being: A moderated mediational model", Journal of Happiness Studies, Vol. 20 No. 1, pp. 251-268.

Linley, P. A., Maltby, J., Wood, A. M., Osborne, G. and Hurling, R. (2009), "Measuring happiness: The higher order factor structure of subjective and psychological well-being measures", Personality and Individual Differences, Vol. 47, pp. 878-884.

Mannheim, B. (1975) "A comparative study of work centrality, job rewards and satisfaction", Sociology of Work and Occupations, Vol. 2, pp. 79-101.

Myers, D. G. and Diener, E. (1995) "Who is happy?”, Psychological Science, Vol. 6, pp. 10-19.

Near, J. P. and Rechner, P. L. (1993) "Cross-cultural variations in predictors of life satisfaction: An historical view of differences among West European countries", Social indicators research, Vol. 29 No.1, pp. 109-121.

Rode, J. C. (2004) "Job satisfaction and life satisfaction revisited: A longitudinal test of an integrated model", Human relations, Vol. 57 No. 9, pp. 1205-1230.

Ruiz-Quintanila, S. A. (1990) "Major work meaning patterns toward a holistic picture" in U. Kleinbeck, H. Henning Quast, H. Thierry, \& H. Hacker (Eds.), Work motivation. Hillsdale, NJ: Lawrence Erlbaum.

Saal, F. E. (1978) "Job involvement: A multivariate approach", Journal of Applied Psychology, Vol. 63, pp. 53-61.

Steiger, J.H. (2007) "Understanding the limitations of global fit assessment in structural equation modeling", Personality and Individual Differences, Vol. 42 No. 5, pp. 893-98. 
Tabachnick, B.G. and Fidell, L.S. (2007) Using Multivariate Statistics, (5th ed.), New York: Allyn and Bacon.

Unanue, W., Gómez, M. E., Cortez, D., Oyanedel, J. C. and Mendiburo-Seguel, A. (2017) "Revisiting the link between job satisfaction and life satisfaction: The role of basic psychological needs", Frontiers in psychology, Vol. 8, p. 680. 